\title{
Ranking Border Cities in Terms of Enjoying Cultural Programs (Case Study: Sardasht City)
}

\author{
Jamal Mohammadi \\ Assistant Professor, Department of Geography and Urban Planning, Faculty of Geography \\ and Planning Sciences, University of Isfahan
}

Mohammad Rasoli

M.A. Student of Geography and Urban Planning, Department of Geography and Urban Planning, Faculty of Geography and Planning Sciences, University of Isfahan,

(Corresponding Author) Email: m626644@gmail.com

Doi:10.5296/jsr.v5i2.6735 URL: http://dx.doi.org/10.5296/jsr.v5i2.6735

\begin{abstract}
Cultural service is considered as one of the main elements of cultural development which seems necessary for justification in the distribution of proper models for balanced distribution of services, population and settlements (spatial balance). The objective of the present study is to investigate how the neighborhoods of Sardasht City enjoy cultural indices in order to achieve the degree of inequality of the neighborhoods. The dominant approach over the present study is the descriptive-analytical method. The population of the study is the neighborhoods of Sardasht ranked based on 16 indices. The studied indices were weighted using AHP model and they were ranked in terms of cultural indices using TOPSIS and the map of neighborhoods' development levels was designed employing GIS.

The findings of the research indicate that there is a significant difference among neighborhoods of Sardasht City in terms of enjoying cultural facilities in such a way that the Neighborhood ShivehEbrahim with the score 0.05576 and GahRagehAshan with the score 0.16274 are in the lowest levels and assign to themselves the development property. On the other hand, the Neighborhood Sarcheshmeh with the score 0.61802 is ranked in the highest level and requires the last development priority.
\end{abstract}

Key words: cultural indices, cultural programs, TOPSIS, AHP, Sardasht City.

\section{Introduction}

Relative local and regional capabilities and privileges are different due to being influenced by different economic, social and environmental factors and this issue causes the priority of some regions over others. Therefore, to conduct different economic, social and cultural programs, the development of strategies of development, success in planning and executive projects, investigation and identification of capabilities, shortages and determination of development levels of regions and settlements based on a series of prior indices seem an inevitable necessity. 


\section{Macrothink}

When the imbalance in spatial distribution of development indices increases severely and results in the spatial imbalance of facilities and population, causes the movement of population and facilities from deprived regions as well as it causes the high concentration of indices in points where suffer from the challenge of concentration.

The requirement of this process is to study and identify attentively the regions and potential and actual capacities as well as to evaluate and identify the relationship between effective indices in developing regions. In this line, to attain this stage, different methods and techniques should be employed. One of the most important techniques in quantitative one (Mohammadi, 2002: 43).

\section{Research Importance}

The necessity of conducting the present research is due to the fact that by investigating and analyzing spatially the available cultural facilities in neighborhoods of Sardasht City, the shortages andirregular density can be found out. In addition, it can be identified that in what level each of urban zones are in terms of enjoying mentioned facilities. Therefore, investigating how development indices of cultural services are distributed in different geographical spaces and determining the potentials and weaknesses cause that the balance in distributing cultural facilities be better identified. Accordingly, the present study is to analyze the mentioned indices by employing different techniques (TOPSIS, AHP, GIS) to achieve the balanced development of regions by identifying how selected indices are distributed in regions.

\section{Research hypothesis}

It seems that the services have not distributed equally in the city.

It seems that the concentration of cultural services in the city is based on how the city is spreading out.

\section{Review of literature}

Dadashpoor and Rostami (2011) in their research titled as "investigating and analyzing how public services are distributed from the perspective of spatial justice (case study: Yasuj City)" by employing Access Network Analysis for the criterion of residents' access to urban services and for the criterion of residents' need to urban services, the AHP was used. The results indicated an $87 \%$ access of residents to urban services. However, the inequality of the degree of access cultural services in the city is obvious.

Mousavi and Hekmatnia (2005), by employing factor analysis and synthesis of indices, determined the factors effective on the development of regions in Iran. In this research, 38 indices were reduced into 6 factors using advanced statistical methods in such a way that the proportion of each factor was identified in human development (Mousavi and Hekmatnia, 2005: 55).

Taghvaei and GhaedRahmati (2006), in a research titled as "analyzing the indices of cultural development in Iran's provinces" evaluated the indices of cultural development and indicated development levels of provinces in terms of cultural spaces and facilities. The results of the research indicate that there is a significant difference among Iran's province in terms of 
cultural spaces and facilities (Taghvaei and GhaedRahmati, 2006: 117-132).

Tirband and Azani (2010), in an article titled as "distribution of facilities and urban services based on social justice (case study: Yasuj City)", investigated different indices among which the degree of access to urban services and value added of lands are the most important. The findings of the research indicate that the zones of Yasuj city have no difference in terms of access to urban facilities and services. Land prices and consequently land value added follow significantly the discussed indices; the provided services are distributed fairly based on the situation and the mode of development of the city.

\section{Theoretical framework}

Culture is a complicated set of sciences, knowledge, arts, thoughts, beliefs, regulations and laws, customs, traditions and in general, all habits and customs which a human being obtains as a member of his society and the society has commitmentsand duties regarding him (SeyyedJavadin, 2004: 611).Zevede states that culture includes all habits of a society or if one considers the society as a set of organized individuals who have particular lifestyle, culture means lifestyle then (Zevede, 2000: 6).

\section{The relationship of cultural programs and urban planning}

Planning is a conscious action to access determined objectives and conduct a series of measures and activites related to each other in future. In addition, planning means prediction; the objective of planning is to predict the best image of future and determine the ways of attaining it during different stages. ingeneral, planning is considered as the most fundamental instrument for attaining development and covers a set of decisions and policies for proper and logical utilization from facilities and resources in line with promoting social life. Such a process in regional and national levels or in urban and rural levels is to operationalize the theoretical and ideal objectives (Rezvani, 2002: 2). According to Evans, Cultural planning is "allocation of resources, distribution of subsidies and public facilities designed and encouraged for a set of artistic activities (theaters, galleries, museums, concert halls, art and media centers, movies and etc.) and the support of artists and cultural staff" (Salehi, Amiri and AzimiDolatabadi, 2008: 87-88). To do so, a framework is designed to indicate diverse fields which open the attitude of cultural planning regarding policies facing us (Comedia, 1991: 78). Therefore, two concepts of cultural and urban planning have a closely relationship in such a way that cultural planning is placed within the other and represents planning and management of social and cultural physical and typical (Torabi and Shirasb, 2004: 9-10).

\section{The role of cultural spaces in cities}

Culture is considered as the bases of human behaviors and a large part of economic behaviors is founded in these bases. Economic development requires doing particular behaviors in different fields of human life and depends heavily the culture and cultural beliefs. Therefore, in the symbol of the tree of economic development, the root of this tree is cultural beliefs (Azimi, 2004: 183). Urban spaces is the support and mirror of thought, culture, nature and is reflective of the range of social objectives, technology, values and human institutions (Harvey,1996). Cultural spaces are constructions which are constructed with a particular 
criterion for cultural usage and in which facilities and instruments of this usage are applied (Tabarsa and Fathi, 2002).

The cultural spaces of cities are messages beyond economic and commercial messages and are full of internal feelings, memoirs and necessary contents for social and cultural contexts (Delvan, 1983: 400). The most important issue attractive in this approach is the way of matching the vast range of cultural resources for contribution in spatial development including local, regional or urban ones. Urban planning should be re-defined based on the process of cultural production and the features of this process should be considered seriously (Buchani, 2006). These spaces are repellents of disorders and social damages and have unique feature and capabilities in reviving civil life and is the flourish of urban life flow. Therefore, cultural spaces which are shaped for the intention of the dynamicity of the economic and social life in urban centers, should be spaces for reinforcing the presence of citizens in public domains.

\section{Introducing the studied scope}

Sardasht Township is one of the border and Kurdish townships of West Azerbaijan Province located in the south of the province neighboring Iraq. The capital of this township is Sardasht City and its population is equal as 41700 according to the census in 2011.

The city is located at the 1500 meter height of sea level and its location is in such a way that is surrounded by mountains and among all constructed levels of the city, 44 percent of the levels is constructed on the ground of 1500 to 1546 meters high and 28 percent on the ground of 1453-1500 meters high. Comparing to the urban development standards, about 40 to 50 percent of the city are located on unfavorable height. The slope of the lands inSardashtCity on the hillside adjacent to a relatively deep hill in the east of the city, peaks and valleys and its unevenness result in the diversity of slopes at the surface of the city; about 62 percent of the surface of the city is located on a 0 to 19 percent slope, 30.87 percent on a 19-38 slope and 5.52 of its surface is located on a $38-57$ percent slope. The rest of the city surface (1.58 percent) is located in a slope higher than 57 percent. Comparing urban development standards, about 40 to 50 percent of the city surface is located on unfavorable locations (Fahar, 2008: 68 and 69). Sardasht City is one of old and mountainous cities. Due to its topographical features and it is a border city, it is less considered in terms of planning and designing and most of its constructions are located in one area of the city due to inappropriate locating in such a way that traffic is not disturbed in spite of smallness of the city. 


\section{MInstitute Macrothink $^{\text {ming }}$}
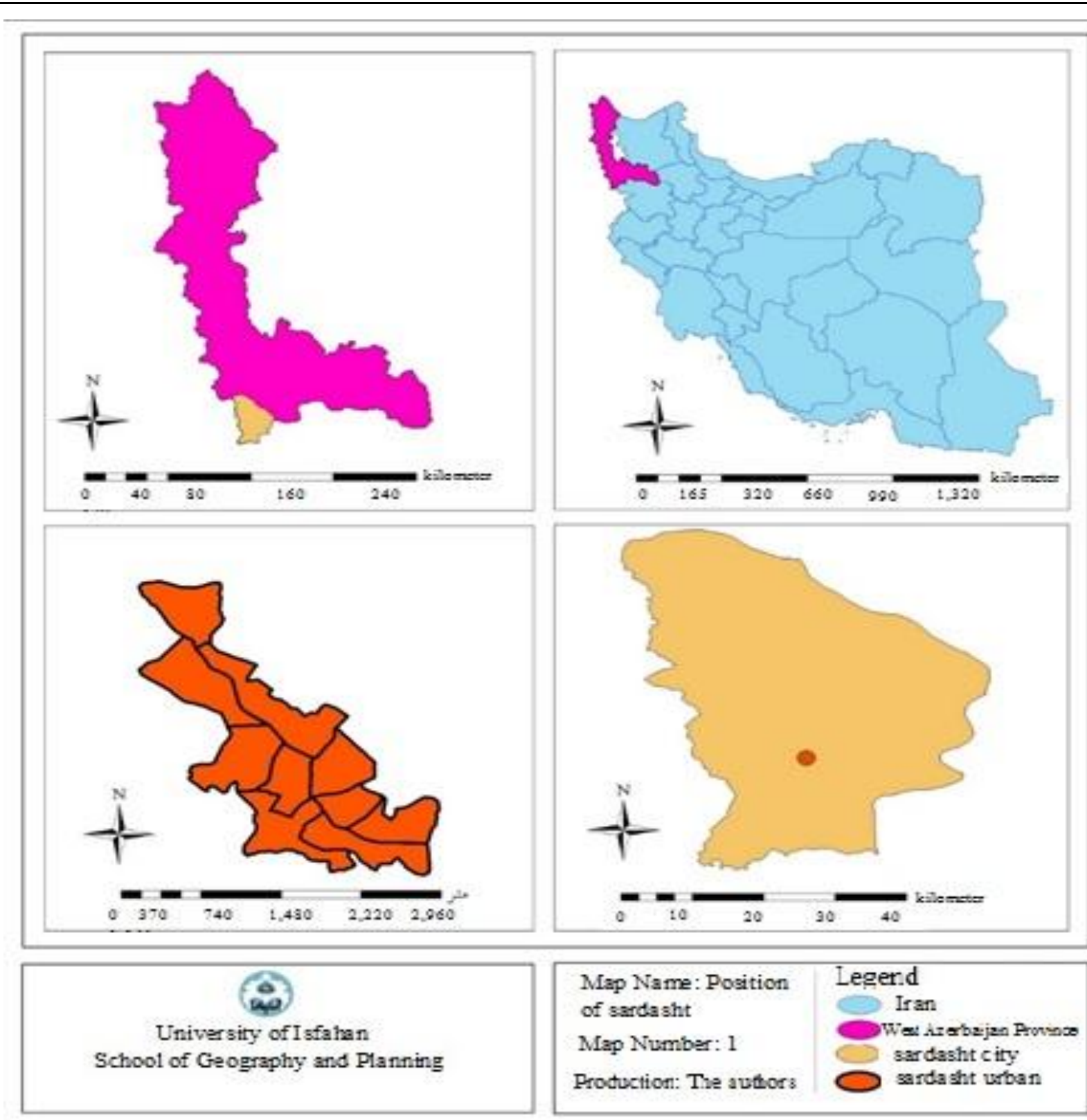

\section{Introducingth employed techniques}

TOPSIS

Although in discussions of decision making in development planning different methods are considered for prioritizing phenomena in terms of development and ranking them, the ranking methods based on ideal solution is one of the most applicable and suitable methods for prioritizing phenomena in terms of enjoying facilities, equipment and etc. due to the importance of the issue, the TOPSSIS model is introduced as follows:

In recent years, researchers including rural development planners started to use Multiple Criteria Decision Making (MCDM)models for decision making because in these decision making models, instead of using one evaluation criterion, multiple criteria are used, these decision making models are divided into two main groups: 
Multiple Objective Decision Making models

Multiple-criteria decision-making models

Multiple Objective Decision Making models mostly are used to design the multiple criteria models and to evaluate alternatives ad select alternative or better ones. A multiple criteria decision making issue principally can be summarized in a decision making matrix whose rows are different alternatives and columns are the criteria which determine the fractures of the alternatives. In addition, the cells of the matrix indicate the location of row alternatives relative to the related columnar criterion. As stated earlier, to determine and prioritize the criteria, alternatives should be prioritized for decision making. For multiple-criteria decision making, there are many models and each of them have particular features with its own advantages and disadvantages. On the other hand, in decision making, the issue of the weight of a criterion is important. It means that if the weight of criteria is identified (the effect of each alternative is equally effective on the level of priority), the weights are considered in calculations. Otherwise, it was necessary to use the experts and elites of a certain section or the techniques of weighting for determining the weight of each criterion. Therefore, each issue of multiple-criteria decision making is faced two problems of selecting a decision making technique and selecting weighting techniques. The history of suing this model refers to 1981 when was designed by Huang and Yun for selecting an alternative among the available alternatives in multiple-criteria decision making. In this method $\mathrm{m}$ alternative are evaluated by $\mathrm{n}$ criteria (Taherkhani, 2007).

\section{AHP model}

MADM methods are different. Each has particular methods for attaining weights. One of these methods is AHP which acts using methods and techniques of eigenvectorsbasedonpaired comparisons.

One of the most efficient techniques of decision making is Analytical Hierarchy Process(AHP) which for the first time, an Iraqi scholar called Thomas Al-Sa'ati proposed in 1980 in management science. It is based on paired comparisons and gives the possibility of investigating different scenarios. Contrary to models such as linear programming, Integer programming, nonlinear programming and classical models of Operations Research consider only one criterion such as benefit, cost, utilization, time and etc. in some cases, the results are favorable when decision making is analyzed based on multiple criteria.

It has been justified that this method is suitable for decision making models in which one alternative is selected from limited alternatives and is used for transforming subjective evaluation to relative values.

AHP is a method in which a complicate situation is analyzed into smaller parts, then these parts are placed in a hierarchical structure. In this method, subjective judgments are assigned numerical values regarding the importance of each variable and the most important variables are identified. 


\section{Evaluated criteria}

In the present study, the following 16 criteria were used:

1. The number of cultural products per population equals 10000 individuals

2. The number of coffee nets per population equals 10000 individuals

3. The number of libraries per population equals 10000 individuals

4. The number of offices per population equals 10000 individuals

5. The number of mosques per population equals 10000 individuals

6. The number of Sportsper population equals 10000 individuals

7. The number of SocialServicesper population equals 10000 individuals

8. The number of Printing andTgsyrper population equals 10000 individuals

9. The number of Service offices per population equals 10000 individuals

10. The number of CentersEducation per population equals 10000 individuals

11. The per capita coffee nets' spaces

12. The per capita libraries' spaces

13. Per capita mosques' spaces

14. Per capita sport spaces

15. Per capita social services' spaces

16. Per capita educational centers' spaces 


\begin{tabular}{|r|r|r|}
\hline Username & $\begin{array}{c}\text { Dedicatedspacef } \\
\text { orha }\end{array}$ & \multicolumn{2}{|c|}{ Percent } \\
\hline Residential & 98.28 & 44.73 \\
\hline Office & 8.61 & 3.91 \\
\hline Military & 42.38 & 19.29 \\
\hline Transportation & 3.62 & 1.64 \\
\hline Business & 5.98 & 1.92 \\
\hline Installations & 4.22 & 1.62 \\
\hline Health & 3.58 & 5.19 \\
\hline Learning & 11.42 & 3.98 \\
\hline Sports & 8.76 & 13.48 \\
\hline Park & 29.62 & 1.45 \\
\hline Cultural & 3.2 & \\
\hline Collect & 219.67 & \\
\hline & & \\
\hline & & \\
\hline & & \\
\hline & & \\
\hline & & \\
\hline
\end{tabular}

Table1: EachareaoflandintheCityExposed

As indicated in the above table, the residential usage with 44.73 hectares is in the first rank and allocates to itselfthe most space of the city, martial usage with 19.29 hectare is in the second rank, green spaces and parks with 13.48 hectares are in the third rank are the three first usages with a great difference from other usages, while transportation usage with 1.64 hectares, hygiene usage with 1.62 hectares, and cultural usages with 1.45 hectares allocate to themselves the least spaces of the city.

To achieve and identify the situation of cultural development (enjoying cultural spaces and facilities) better the studied regions and determining the priority of development and construction in these regions using TOPSIS as a disciplined are evaluated regarding their familiarities with ideal solutions and conducted calculations, the regions were evaluated and 10 neighborhoods of the city were categorized into five rankings. 
Table2: Spatial distribution parameters Cultural Services

\begin{tabular}{|c|c|c|c|c|c|c|c|c|c|c|c|c|c|c|c|c|}
\hline $\begin{array}{l}0 \\
0 \\
0 \\
0 \\
\frac{0}{0} \\
0 \\
\frac{0}{00} \\
0.00 \\
\overline{0}\end{array}$ & 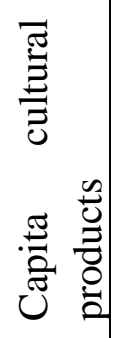 & Uֶ, & 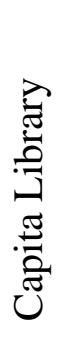 & 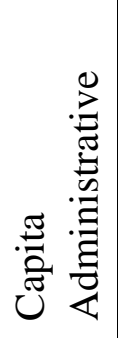 & 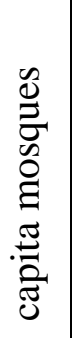 & 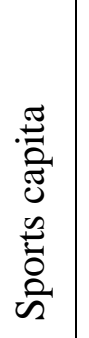 & 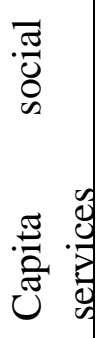 & 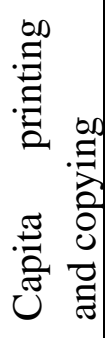 & 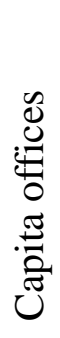 & 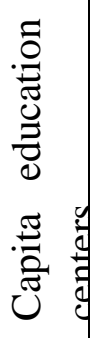 & 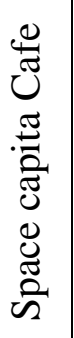 & 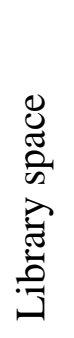 & $\begin{array}{l}0 \\
\tilde{z} \\
0 \\
0 \\
0 \\
0 \\
\tilde{0} \\
\tilde{0} \\
\sum_{0}^{0}\end{array}$ & 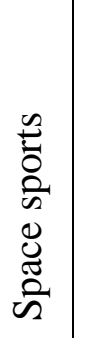 & 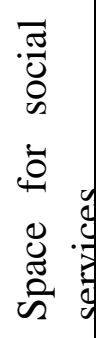 & 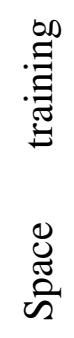 \\
\hline 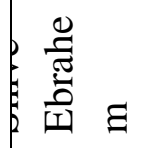 & \begin{tabular}{l}
\multirow{2}{~}{} \\
லै \\
0
\end{tabular} & 0 & 0 & 0 & 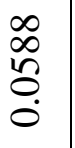 & ญे & 0 & 0 & 0 & 0 & 0 & 0 & 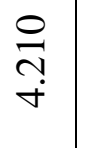 & $\begin{array}{l}\frac{n}{0} \\
\end{array}$ & 0 & 0 \\
\hline : & 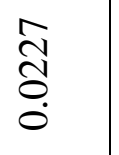 & $\begin{array}{l}n \\
\stackrel{n}{0} \\
\stackrel{0}{0}\end{array}$ & $\begin{array}{l}\text { ป̂ } \\
0 \\
0\end{array}$ & $\begin{array}{ll}0 & a \\
m & \\
\stackrel{0}{0} & \end{array}$ & $\begin{array}{l}n \\
\stackrel{n}{0} \\
0 \\
0\end{array}$ & ปิ & $\begin{array}{l}\stackrel{n}{0} \\
\stackrel{0}{0}\end{array}$ & 0 & 0 & 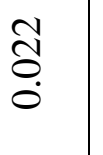 & $\begin{array}{l}\text { d } \\
\infty \\
\text { r. } \\
\text { r. }\end{array}$ & $\stackrel{0}{a}$ & $\begin{array}{l}\text { ते } \\
\infty \\
\text { ஸे }\end{array}$ & $\stackrel{0}{a}$ & $\begin{array}{l}\text { กิ } \\
\infty \\
\dot{m}\end{array}$ & 0 \\
\hline 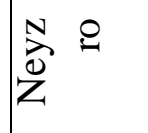 & 0 & 0 & 0 & $\frac{8}{0}$ & 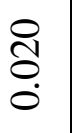 & $\begin{array}{l}\stackrel{0}{0} \\
\text { ర. }\end{array}$ & $\begin{array}{l}\circ \\
0 \\
0 \\
0\end{array}$ & 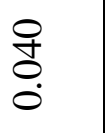 & 0 & 0 & 0 & 0 & ָે & તે & సે & $\begin{array}{l}\infty \\
\dot{\Xi}\end{array}$ \\
\hline 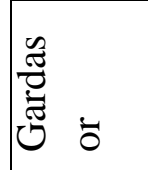 & in & 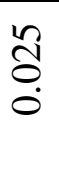 & 0 & $\stackrel{\circ}{\stackrel{n}{0}}$ & \begin{tabular}{l}
$\stackrel{0}{n}$ \\
\hdashline \\
0
\end{tabular} & $\begin{array}{l}\stackrel{0}{\circ} \\
0 \\
0\end{array}$ & 0 & $\stackrel{\circ}{ஜ}$ & 0 & 0 & 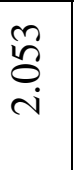 & 0 & 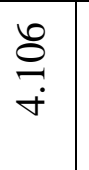 & 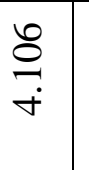 & 0 & 0 \\
\hline 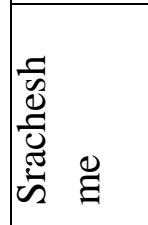 & 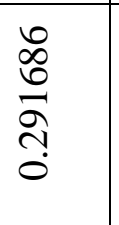 & 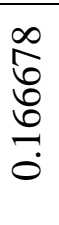 & 0 & $\begin{array}{l}\frac{\infty}{10} \\
0 \\
0 \\
0 \\
0\end{array}$ & $\begin{array}{l}\text { ñ } \\
\text { } \\
\text { ñ } \\
0\end{array}$ & 0 & 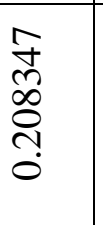 & 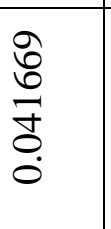 & 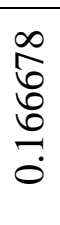 & 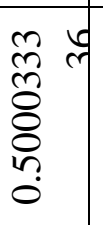 & 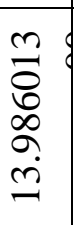 & 0 & $\begin{array}{l}\vec{n} \\
n \\
\infty \\
0 \\
\dot{0} \\
\dot{m}\end{array}$ & 0 & 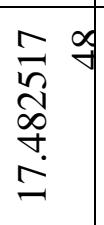 & 0 \\
\hline 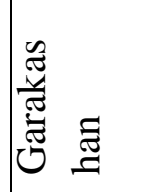 & $\begin{array}{l}\overline{0} \\
\bar{\sigma} \\
0 \\
0\end{array}$ & 0 & 0 & $\begin{array}{l}n \\
n \\
n \\
0 \\
0\end{array}$ & $\begin{array}{l}\overline{0} \\
\bar{\Xi} \\
\\
0\end{array}$ & 0 & 0 & 0 & 0 & 0 & 0 & 0 & $\begin{array}{l}\vec{n} \\
\tilde{n} \\
\hat{\infty} \\
a \\
\dot{\gamma}\end{array}$ & 0 & 0 & 0 \\
\hline 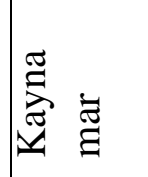 & \begin{tabular}{l}
$n$ \\
\multirow{2}{n}{} \\
0 \\
0
\end{tabular} & 0 & 0 & \begin{tabular}{l}
$n$ \\
\multirow{2}{n}{} \\
0 \\
0
\end{tabular} & 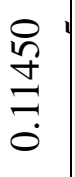 & 0 & $\begin{array}{l}0 \\
\stackrel{0}{9} \\
\exists \\
\\
0\end{array}$ & 0 & 0 & 0 & 0 & 0 & $\begin{array}{l}m \\
m \\
m \\
m \\
m\end{array}$ & 0 & $\begin{array}{l}m \\
\text { ले ले } \\
m \\
m\end{array}$ & 0 \\
\hline 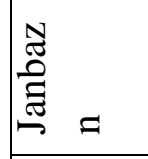 & 0 & 0 & 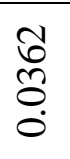 & $\begin{array}{l}\stackrel{+}{\mathbb{N}} \\
\stackrel{0}{0}\end{array}$ & 0 & 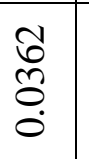 & 0 & 0 & 0 & 0 & 0 & 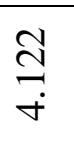 & 0 & $\underset{\underset{+}{J}}{\stackrel{\Xi}{+}}$ & 0 & 0 \\
\hline 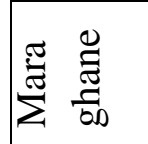 & 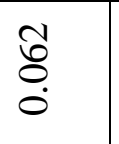 & 0 & 0 & 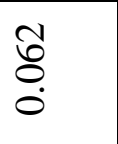 & 0 & 0 & 0 & 0 & 0 & 0 & 0 & 0 & 0 & 0 & 0 & 0 \\
\hline 壱 $\frac{y}{3}$ & 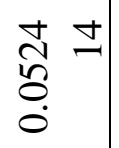 & 0 & 0 & 0 & 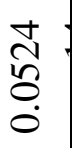 & 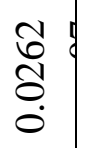 & 0 & 0 & 0 & 0 & 0 & 0 & \begin{tabular}{l}
$n$ \\
\multirow{2}{n}{} \\
$n$ \\
$n$
\end{tabular} & 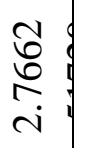 & 0 & 0 \\
\hline
\end{tabular}




\begin{tabular}{|c|c|c|c|c|c|c|c|c|c|c|}
\hline ndicators & $\begin{array}{c}\text { Capita } \\
\text { cultural } \\
\text { products }\end{array}$ & $\begin{array}{c}\text { Capita } \\
\text { Cafe }\end{array}$ & $\begin{array}{l}\text { Capita } \\
\text { Library }\end{array}$ & $\begin{array}{c}\text { Capita } \\
\text { Administrative }\end{array}$ & $\begin{array}{l}\text { capita } \\
\text { mosques }\end{array}$ & $\begin{array}{l}\text { Sports } \\
\text { capita }\end{array}$ & $\begin{array}{c}\text { Capita } \\
\text { social } \\
\text { services }\end{array}$ & $\begin{array}{c}\text { Capita } \\
\text { printing } \\
\text { and } \\
\text { copying }\end{array}$ & $\begin{array}{l}\text { Capita } \\
\text { offices }\end{array}$ & $\begin{array}{c}\text { Capita } \\
\text { education } \\
\text { centers }\end{array}$ \\
\hline $\begin{array}{c}\text { Capita cultural } \\
\text { products }\end{array}$ & 1 & 1 & 3 & 0.2 & 1 & 1 & 3 & 3 & 0.2 & 0.2 \\
\hline Capita Cafe & 1 & 1 & 3 & 0.2 & 1 & 1 & 3 & 3 & 0.2 & 0.2 \\
\hline Capita Library & 0.333333 & 0.333333 & 1 & 0.166667 & 0.5 & 0.5 & 1 & 1 & 0.166667 & 0.166667 \\
\hline $\begin{array}{c}\text { Capita } \\
\text { Administrative }\end{array}$ & 5 & 5 & 6 & 1 & 5 & 5 & 6 & 6 & 1 & 1 \\
\hline $\begin{array}{c}\text { capita } \\
\text { mosques }\end{array}$ & 1 & 1 & 2 & 0.2 & 1 & 1 & 3 & 3 & 0.2 & 0.2 \\
\hline Sports capita & 1 & 1 & 2 & 0.2 & 1 & 1 & 3 & 3 & 0.2 & 0.2 \\
\hline $\begin{array}{c}\text { Capita social } \\
\text { services }\end{array}$ & 0.3333 & 0.333333 & 1 & 0.166667 & 0.333333 & 0.333333 & 31 & 1 & 0.166667 & 0.166667 \\
\hline $\begin{array}{l}\text { apita printing } \\
\text { and copying }\end{array}$ & 0.333333 & 0.333333 & 1 & 0.166667 & 0.333333 & 0.333333 & 31 & 1 & 0.166667 & 0.166667 \\
\hline Capita offices & 5 & 5 & 6 & 1 & 5 & 5 & 6 & 6 & 1 & 1 \\
\hline $\begin{array}{c}\text { Capita } \\
\text { education } \\
\text { centers }\end{array}$ & 5 & 5 & 6 & 1 & 5 & 5 & 6 & 6 & 1 & 1 \\
\hline
\end{tabular}

Table3: Indices associated with ahp model

Table4: Weight indices in AHP model

\begin{tabular}{|l|l|}
\hline \multicolumn{1}{|c|}{ Index } & \multicolumn{1}{c|}{ Weight } \\
\hline Administrative & 0.227989 \\
\hline $\begin{array}{l}\text { Printing and } \\
\text { reproduction }\end{array}$ & 0.0266499 \\
\hline Social service & 0.0266499 \\
\hline Agency & 0.227989 \\
\hline Cafes & 0.059948 \\
\hline Library & 0.0284971 \\
\hline Cultural products & 0.059948 \\
\hline Training centers & 0.227989 \\
\hline Mosques & 0.0571702 \\
\hline Athletic ios & 0.0571702 \\
\hline
\end{tabular}


Table5: Scalingindices

\begin{tabular}{|c|c|c|c|c|c|c|c|c|c|c|c|c|c|c|c|c|}
\hline & 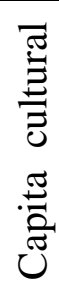 & 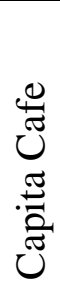 & 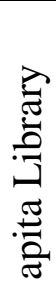 & שี & 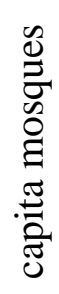 & 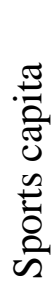 & 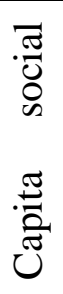 & 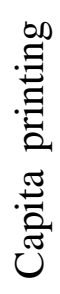 & 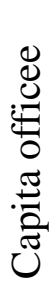 & שَّ & 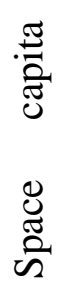 & 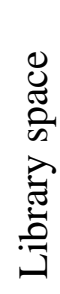 & 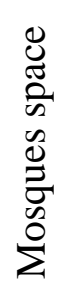 & 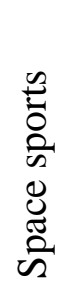 & 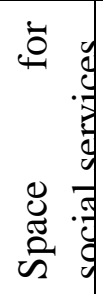 & 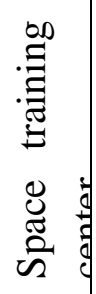 \\
\hline 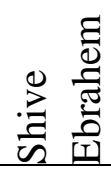 & : & 0 & 0 & 0 & $\begin{array}{l}\bar{\infty} \\
\stackrel{8}{8} \\
\stackrel{0}{0}\end{array}$ & 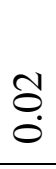 & 0 & 0 & 0 & 0 & 0 & 0 & 8 & $\underset{0}{0}$ & 0 & 0 \\
\hline$\stackrel{\Xi}{\Xi}$ & \&: & ठ․ & $\stackrel{0}{0}$ & $\stackrel{0}{0}$ & 8 & ठㅁ & $\stackrel{8}{8}$ & 0 & 0 & o. & ర্) & ọ. & $\stackrel{8}{8}$ & $\ddot{\circ}$ & $\stackrel{8}{8}$ & 0 \\
\hline $\begin{array}{l}\text { O } \\
\text { 岕 } \\
\text { Z }\end{array}$ & 0 & 0 & 0 & $\begin{array}{l}\stackrel{n}{n} \\
\text { ó } \\
\dot{0}\end{array}$ & $\begin{array}{l}\hat{\widehat{\Omega}} \\
\stackrel{8}{0} \\
\dot{0}\end{array}$ & $\begin{array}{l}\stackrel{\nabla}{*} \\
\stackrel{0}{0}\end{array}$ & 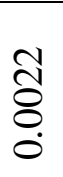 & $\begin{array}{l}\stackrel{\oplus}{0} \\
\stackrel{0}{0}\end{array}$ & 0 & 0 & 0 & 0 & $\stackrel{9}{\frac{9}{8}}$ & $\begin{array}{l}\stackrel{8}{8} \\
\stackrel{8}{0}\end{array}$ & $\begin{array}{l} \pm \\
\stackrel{8}{8} \\
\stackrel{0}{0}\end{array}$ & 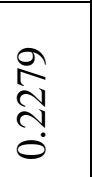 \\
\hline 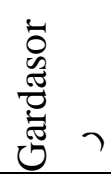 & $\begin{array}{l}\text { f } \\
8 \\
0\end{array}$ & $\begin{array}{l}0 \\
\infty \\
8 \\
0 \\
0\end{array}$ & 0 & $\stackrel{2}{\cong}$ & $\begin{array}{l}\text { oे } \\
8 \\
8 \\
0\end{array}$ & $\begin{array}{l}\overline{0} \\
\text { ஸొ } \\
0\end{array}$ & 0 & $\stackrel{1}{\circ}$ & 0 & 0 & $\begin{array}{l}\stackrel{1}{\infty} \\
\stackrel{8}{8} \\
\stackrel{0}{0}\end{array}$ & 0 & $\begin{array}{l}n \\
8 \\
8 \\
0\end{array}$ & 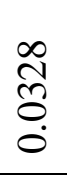 & 0 & 0 \\
\hline 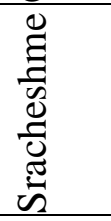 & 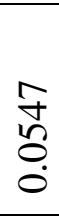 & $\begin{array}{l}N \\
\hat{n} \\
0 \\
0\end{array}$ & 0 & 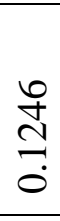 & $\begin{array}{l}\stackrel{0}{n} \\
0 \\
0\end{array}$ & 0 & 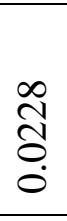 & $\begin{array}{l}\stackrel{n}{ \pm} \\
0 \\
0\end{array}$ & $\begin{array}{l}\stackrel{\curvearrowright}{N} \\
\stackrel{N}{0}\end{array}$ & 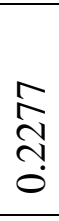 & $\begin{array}{l}\frac{N}{\hat{n}} \\
0 \\
0\end{array}$ & 0 & $\begin{array}{l}0 \\
\stackrel{0}{n} \\
0 \\
0\end{array}$ & 0 & $\begin{array}{l}\infty \\
\stackrel{0}{0} \\
0 \\
0\end{array}$ & 0 \\
\hline 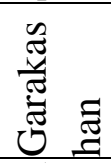 & $\begin{array}{l}m \\
0 \\
0\end{array}$ & 0 & 0 & $\begin{array}{l}0 \\
0 \\
0\end{array}$ & $\underset{0}{8}$ & 0 & 0 & 0 & 0 & 0 & 0 & 0 & 8 & 0 & 0 & 0 \\
\hline 疍 & $\overline{0}_{0}^{0}$ & 0 & 0 & $\begin{array}{l}\text { U. } \\
0\end{array}$ & $\stackrel{\overline{0}}{0}$ & 0 & $\begin{array}{l}\overline{0} \\
0\end{array}$ & 0 & 0 & 0 & 0 & 0 & O̊ & 0 & o. & 0 \\
\hline $\begin{array}{l}\text { సี } \\
\text { స్ } \\
\text { స్ }\end{array}$ & 0 & 0 & $\begin{array}{l}\text { Oे } \\
0\end{array}$ & $\begin{array}{l}n \\
0\end{array}$ & 0 & $\begin{array}{l}\text { Oे } \\
0\end{array}$ & 0 & 0 & 0 & 0 & 0 & $\underset{0}{0}$ & 0 & $\stackrel{n}{0}$ & 0 & 0 \\
\hline 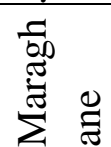 & ర0. & 0 & 0 & $\begin{array}{l}0 \\
0\end{array}$ & 0 & 0 & 0 & 0 & 0 & 0 & 0 & 0 & 0 & 0 & 0 & 0 \\
\hline 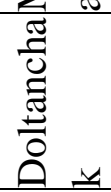 & 8 & 0 & 0 & 0 & $\begin{array}{l}8 \\
8 \\
0\end{array}$ & $\stackrel{0}{0}$ & 0 & 0 & 0 & 0 & 0 & 0 & $\begin{array}{l}8 \\
0\end{array}$ & $\begin{array}{l}\text { Oे } \\
0\end{array}$ & 0 & 0 \\
\hline
\end{tabular}




\section{Macrothink}

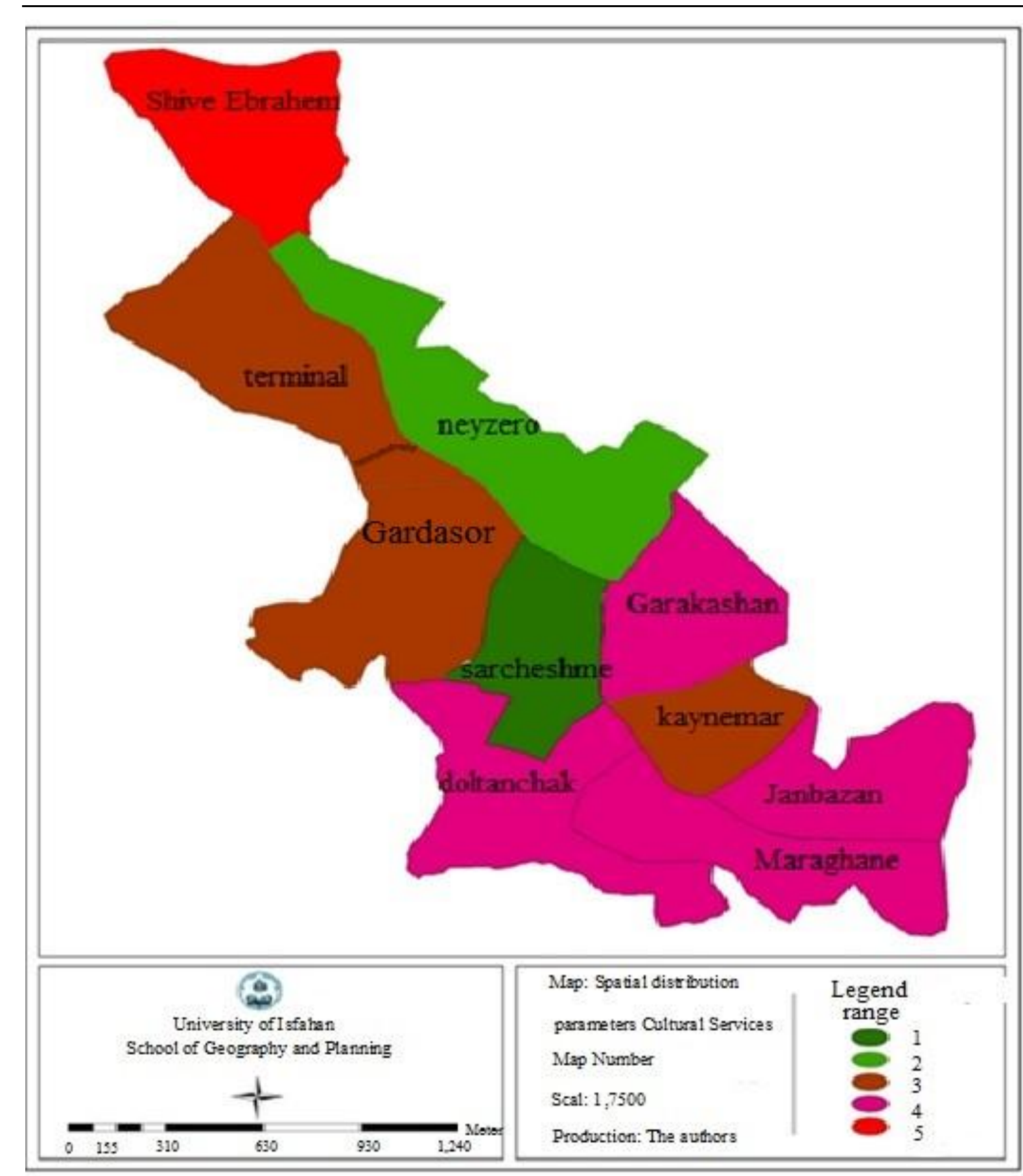

To determine the importance of each of the criteria employed in the present study, in developing cultural plans, the ideas of 20 experts were used. The survey indicates that regarding Sardasht's being a border city and its mountainous situation, the most weight is allocated to the usages of cultural products, coffee nets, sports, and mosques 
Table5: Weight indices in AHP model

\begin{tabular}{|r|c|c|}
\hline ndicators & point & Rank \\
\hline Shive Ebrahem & 0.055762 & 5 \\
\hline Terminal & 0.241723 & 3 \\
\hline Geyzro & 0.365774 & 2 \\
\hline Sracheshme & 0.618027 & 3 \\
\hline Garakashan & 0.162742 & 1 \\
\hline Kaynamar & 0.212875 & 4 \\
\hline Janbazn & 0.194676 & 3 \\
\hline Maraghane & 0.195975 & 4 \\
\hline Doltanchak & 0.177423 & 4 \\
\hline & & \\
\hline & & \\
\hline & & \\
\hline
\end{tabular}

Investigations indicate that Sarcheshmeh Neighborhood in the 16 investigated criteria are more privileged than other neighborhoods and has the first rank in all of them. The only criteria in which Sarcheshmeh is not in the first rank are cultural criteria, libraries, sports, and educational spaces. This issue indicates paying too much attention to this neighborhood compared to other neighborhoods. Regarding the organic structure of the city and its physical development, the primary core of the city has been Sardasht Neighborhood. Therefore, most of the usages are concentrated in this neighborhood and during recent years, no attention has not been paid to the distribution of usages in such a way that 24.37 percent of the usages are concentrated in Sarcheshmeh Neighborhood. With a great difference, 14.63 percent of the cultural products are located in Neizehroo Neighborhood. The rest of the neighborhoods each has less than 10 percent of the services. ShivehEbrahim with 2 percent of enjoying cultural service is located in the lowest rank.

Hypothesis testing and conclusion

1. It seems that cultural services have not been distributed equally in the city.

Investigations indicate that most of the usages are not distributed equally, but they are concentrated in an area. Sarcheshmeh Neighborhood has concentrated the most usages in itself with a great difference from other neighborhoods and in the second rank, Neizehroo, Gardehsour, Terminal are located. ShivehEbrahim has concentered in itself the least usages. 


\section{Mll Macrothink}

This distribution of usages does not causes development, but it prevents development because development is possible when all parts are equally in line with one objective (development). Sardasht City has an organic structure whose each of usages have been developed unsystematically and result in an unbalanced structure of the city and disturb the life in the city. Regarding the results of investigating this hypothesis, it is confirmed.

2. it seems that the concentration of cultural services in the city is consistent with how the city is spread out.

The investigations indicate that regarding the organic structure of the city, the attentions have been paid to the core of the city and most of the usages are concentrated in this area. Then, attentions have been towards the areas of the expansion of the city. Sarcheshmeh (the first core of the city) with a great difference from other regions is in the first rank. It has caused that most of the density of the traffic take place in this area which the most worn-out texture of the city. This neighborhood has been constructedconsidering its oldness and the needs of past years; therefore, it cannot fulfill the requirements of today. In addition, heavy traffic can be observable in this area of the city.

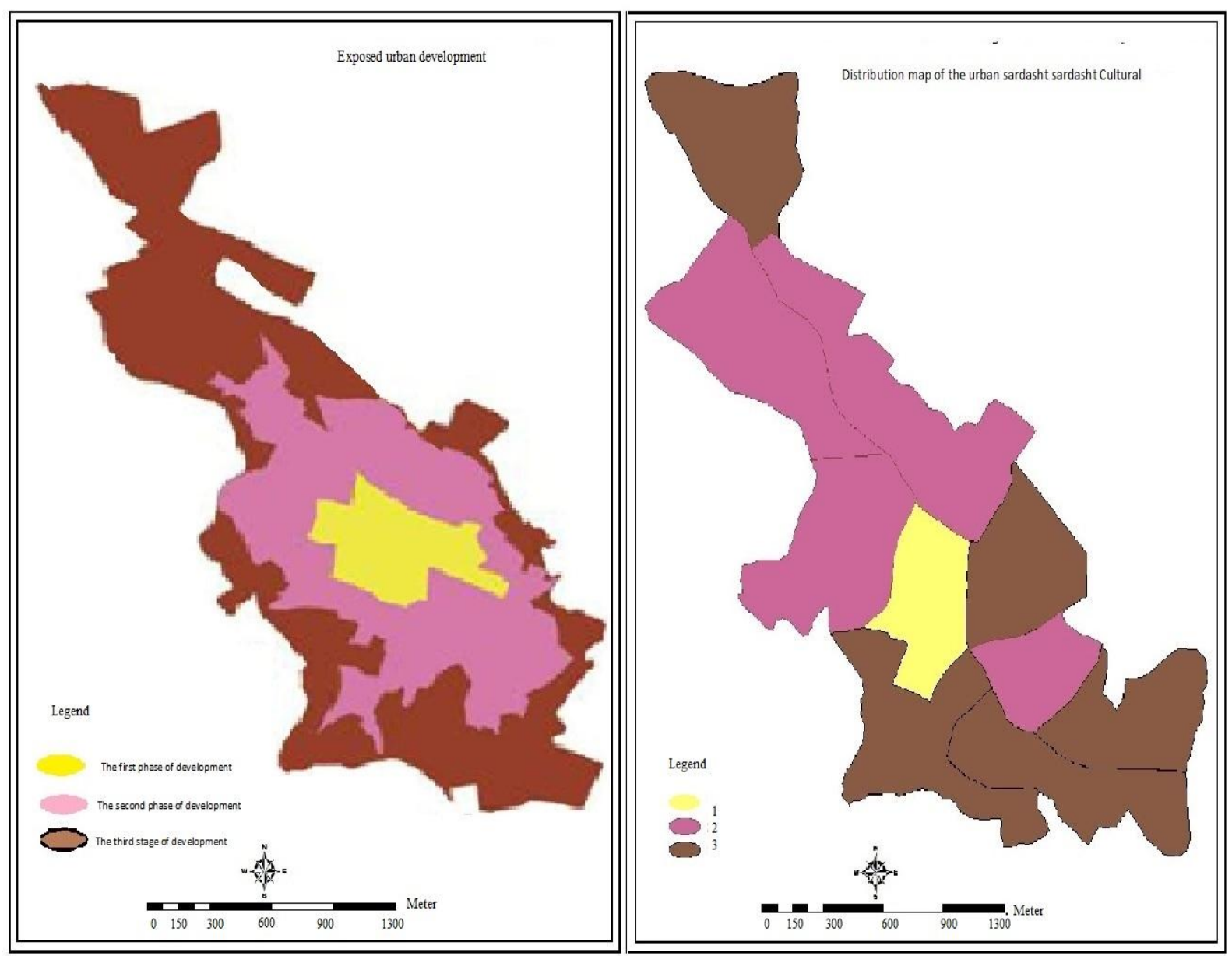

Conclusion

Considering that cultural service is one of the necessary elements of development, i.e. if all instruments and equipment are available for development but the culture is not available, development will not occur. Therefore, for promoting culture, the fair distribution of cultural 
services is one of the pre-requisites of development. Sardasht City can be divided into 5 groups in terms of enjoying cultural service. In this stage, the weaknesses should be sought which in the present study, there are points which are less paid attention to. ShivehEbrahim is placed in the fifth rank in terms of ranking and in the first priority in terms of pursuing and expanding services. Sarcheshmeh with a great difference from other neighborhoods is placed in the first rank in terms of enjoying the services and in the last priority in terms of development. To attain a balanced development in the city it is required that the attentions be paid to more deprived neighborhoods and prevent from giving more facilities to rich neighborhoods. Therefore, it seems that most of urban challenges will be minimized.

\section{Resource}

1. Buchanan, M. H. (1985), Evaluationof non-social spatialTadlᄀHayIlamfrom the perspective ofsustainable development,Shhrdary $\neg$ HaJournal, VolVI, No. 73, Tehran.

2. Torabi, A., Shyrasb, R.(1983), the city's cultural and civicculture, Journal ofResearch, Education, Information,PlanningandUrban Management, Department of the Interior, andDhyary $\neg$ HayShhrdary $\neg$ Hathecountry, a new course, sixth year, No. 64.

3. Taghvai, M., Qaydrhmtysafar, F. (1385), analyzing parameters Astan $\neg$ Hay country's cultural development, and the development of Regional Geography Mjlh $\neg$ Y, No. VII.

4. Dadashpoor, H and Rostami, F. (1990), analyzethe spatialdistributionof justicefrom the perspective ofPublic Utilities(YASUJ case study), Journal of Geographyand DevelopmentNahy $\neg$ Ay, Shmarh $\neg$ Yshanzdhm.

5-Razavi, M.T. (1981), urbanland useplanningprograms, PressSecretary,Tehran1415

6-Rahnamahy, M. T. (1981), adiscussionofurbanism, architectureand urbanismResearchCenterof Iran, Tehran.

7-Salehi Amir, S R and Hazeme dolatabade, O. (1987), Principles of Cultural Policy and Planning, the Expediency Council, Strategic Research Institute, first edition, Tehran

8-Taherkhani, M. (1986), "Application of TOPSIS technique Avlvyt $\neg$ Bndyplaceinthe agri cultural industries in rural areas" Pzhvhsh ᄀHayEconomicQuarterly, VolVI, Issue III.

9-Tabarsa, K. A, and Fathi, B. (1981), review of existing arts and cultural spaces Nyaz $\neg$ Hay society and culture magazine, numbers Pzhhsh.

10-Azimi, H. (1983), The Economics of Underdevelopment Circuits, Fifth Edition, published by Ney.

11-Mohammadi, J. (1981) Quantitative analysis of the concept and its role in urban planning and Tente, Journal of geographical space, Islamic Azad University, Ahar, second year.

12-Mousavi, M and Hkmt Nya H. (1984) "Factor analysis of the factors affecting the development and integration Shakh $\neg$ Ha parts of Iran," Journal of Geography and Development, autumn and winter.

13-Comedia. (1991) Lonon World city: the position of Cutural, London Planning advisory 
Committee.

14-Delevan, W. M. (1983), Adaptation, Variation and Cultural Geography, The Professional Geographer, Volume35, Issue4, Page399-407.

15-Harvey, David(1996), Just, Nature \& The Geography of Difference BlickWell.

16-Zevede, B. (2000) Culture and Personality, Gritian: Blackwell. 